\title{
A PROPÓSITO DE ECOS PETRARQUISTAS EN EL ARGENTINO ENRIQUE BANCHS
}

La talentosa crítica argentina de la Universidad de La Plata, Alma Novella Marani, ha tratado magníficamente este tema en su libro Tonos y motivos italianos en la literatura argentina ${ }^{1}$, refiriéndose a los cien sonetos del gran poeta argentino Enrique Branchs recogidos en el volumen La urna, el que revela (junto a reminiscencias pascolianas a las cuales alude la misma autora, siguiendo a Roberto $\mathrm{F}$. Giusti ${ }^{2}$ ) ecos y presencias del cancionero petrarquista. La crítica argentina ha examinado, con referencias textuales de los dos autores, algunas afinidades y convergencias ("ecos"), tanto a nivel de contenidos como a nivel noético e icónico. Tratemos de reexaminar y completar comparativa y puntualmente, desde un punto de vista lingüístico (léxico, estilístico y semántico) los mismos textos; sin dejar de lado, naturalmente, el soporte icónico, dado que las palabras (excepto las de simple relación) siempre son portadoras de imágenes, las que a su vez, para un poeta, no pueden expresarse si no con palabras. La finalidad de esta tentativa, por cierto, no es la de apuntar a resultados precisos; ni mucho menos, definitivos (se sabe que no es fácil alcanzar la certeza de que determinadas imágenes o estilemas, o determinados momentos creativos de un poeta estén recogidos necesaria y directamente de poetas anteriores). De todos modos, se sabe también que, cuando un verdadero poeta se inspira en un predecesor, lo reinventa, lo representa sub specie novae aeternitatis. El verdadero poeta, aun cuando puede parecer que imita, no imita en realidad; sino que recrea: es el caso de Enrique Banchs respecto a Petrarca. Este rápido examen quiere sobre todo ratificar una me-

${ }^{1}$ Facultad de Humanidades y Ciencias de la Educación, La Plata, 1977, pp. 151 ss.

${ }^{2}$ A. Novella Marani, op. cit., p. 154, n. 8. 
todología y una técnica para conducir este tipo de investigación comparativa con referencia a eventuales y posibles fuentes literarias. Dicho esto, examinaremos, a título indicativo, los pasos más significativos entre los seleccionados por A. Novella; lo que incluso podrá constituir un ejemplo práctico de cómo el crítico comparatista puede servirse de la crítica precedente tomando la misma como punto de partida para su trabajo.

\section{PETRARCA}

Spirito doglioso, errante (mi rimembra), per spelunche deserte e pellegrine, piansi molt'anni il mio sfrenato ardire. .

... ed in un cervo solitario e vago di selva in selva ratto mi trasformo; et ancor de' miei can fuggo lo stormo...

(Canzoniere, Soneto XXIII)

Solo e pensoso i piu deserti, campi vo misurando a passi tardi e lenti... (id., Soneto XXXV)

\section{BANCHS}

Como es de amante necesaria usanza huir la compañia y el rüido, vagaba en sitio solo y escondido como en floresta umbría un ciervo herido.

$\mathrm{Y}$ a fe que aunque cansado de esperanza pedía al bosquecillo remembranza y en cada cosa suya semejanza con el ser que me olvida y que no olvido... (La urna, Soneto 5)

Oh, cuantas veces como yo pasaba, pálido y solitario, y recordaba, lo que entonces podía llamar mío!... . (id., Soneto 35)

Podemos adoptar el método (ya experimentado en trabaji anteriores) de aislar de los textos comparados los elementos idé ticos, los equivalentes y los análogos, tal como sigue:

Elementos idénticos: "rimembra" y "remembranza". 
Elementos equivalentes: "errante [...] per spelunche deserte e pellegrine /[..]/ in un cervo solitario e vago / di selva in selva [...] mi trasformo" y "vagaba en sitio solo y escondido / como en floresta [...] un ciervo herido"; "solo e pensoso" y "pálido y solitario", "va misurando a passi" y "yo pasaba".

Elementos análogos: "ed ancor dei miei can fuggo lo stormo" y "huir la compañía y el rüido".

En Petrarca (P) aparece el participio ("errante") que, como tal, congela la imagen (el verbo usado cualitativamente adquiere el valor de un adjetivo); en Banchs (B) el imperfecto ("vagaba") que disuelve líricamente la imagen connotando duración.

En $\mathrm{P}$ el verbo ("mi rimembra"), en B el sustantivo: "pedía al bosquecillo remembranza" (sustantivación del verbo).

P: "per spelunche deserte e pellegrine", y más abajo: "solo $e$ pensoso i piu deserti campi / [...]"'; B: "en sitio solo y escondido". La imagen psicológica del "solo e pensoso" se transforma en otra más concreta, más contextual, más locativa de "[sitio] solo y escondido"; en una hay referencia al sujeto humano, al poeta; en la otra al sitio, al lugar (del plano psicológico al físico, geográfico, espacial: ontologización de la imagen).

P: "piansi molti anni [...]", B: "oh cuántas veces [...] recordaba". La noción temporal que en uno es durativa ("molti anni"), en el otro es frecuentativa ("cuántas veces"): de la extensión temporal a la intensidad temporal.

$\mathrm{Si}$ en $\mathrm{P}$ aparece líricamente "un cervo solitario e vago [...]", en B encontramos dramáticamente "un ciervo herido" (agudización de la imagen que se vuelve más sufrida, lacerante).

A la inversa, en P: "di selva in selva [...]"; en B: "en floresta umbría [...]"'. La selva insistente y frondosa de uno se convierte, en el otro, en floresta connotada líricamente como umbría (liricización de la imagen).

$Y$, por último, el petrarquista "et ancor dei miei can fuggo lo stormo" encuentra su análogo en el banchiano "huir la compañía y el rüido"': uno huye de la jauría de perros (la confusión, los ladridos); el otro huye de la compañía y el rumor de los hombres. Los dos huyen del alboroto; y la imagen canina, animal, de uno, se vuelve humana en el otro (humanización de la imagen).

Pero, a partir de aquí, para simplificar, y teniendo en cuenta los límites de este trabajo, unificaremos las tres categorías de elementos: idénticos, equivalentes y análogos, bajo la única etiqueta de elementos equivalentes. 


\section{PETRARCA}

Ma pur sì aspre vie nè sì selvagge cercar non so ch'Amor non venga sempre ragionando con meco, et io co' lui...

(Soneto XXXV)

\section{BANCHS}

Sutil maestro su doctrina ha sido $\tan$ elocuente que doquiera creo sentir la voz que sigue mi deseo...

(Soneto 21)

Elementos equivalentes: "Amor" y "sutil maestro"; "veng sempre ragionando con me et io con lui" y "tan elocuente qu doquiera creo /sentir la voz que sigue mi deseo".

El amor petrarquesco (el personaje Amor) se vuelve "sut maestro" y la imagen temporal "sempre" (la continuidad tem poral) se cambia por "doquiera" (la dilatación espacial): de 1 temporalidad a la espacialidad (transferencia de planos ontológ: eos). Mientras en P está el razonar, es decir, el coloquio, el inteı cambio activo de palabras y de sentimientos entre él y el Amc ("ragionando con me et io con lui'"); en B está la recepción, ‘ escuchar la voz del "sutil maestro" ("sentir la voz que sigue n deseo"). En uno encontramos la reciprocidad de la palabra; e el otro, en cambio, el arribo de la palabra (la palabra desead por el receptor): del movimiento de ida y vuelta de la imagen sc nora, al de simple movimiento de ida.

\section{PETRARCA}

Diciasette anni ha già rivolto il cielo...

Oi me lasso! E quando fia quel giorno che mirando il fuggir degli anni mici, esca del fosco e di sì lunghe pene?

Vedrò mai il dì che, pur quant' io vorrei, quell'aria dolce del bel viso adorno piaccia a quet'occhi, e quanto si convene?

(Soneto CXXII)

\section{BANCHS}

Seis años llevo con la misma suerte... Quiero salvarme del doliente estado; mando a mis ojos que no quieran verte; los ojos suaves porque te han mirado!

(Soneto 6) 
Elementos equivalentes: "Diciasette anni" y "Seis años"; "esca [...] di sì lunghe pene" y "salvarme del doliente estado"; "aria dolce" y "ojos suaves"; "quest'occhi" y "mis ojos".

Los diecisiete años de la espera petrarquesca, en B se vuelven seis (restricción temporal). P: "e quando fia quel giorno/ que, [...] / esca del foco e di sì lunghe pene?; y B: "Quiero salvarme del doliente estado". En uno, la pregunta retórica a sí mismo y, en el otro, voluntad de salir del estado de sufrimiento; de la indefinición de la imagen petrarquesca, y toda trabajada sobre la interrogación, a la precisión volitiva de la afirmación de Banchs. Uno se pregunta si podrá alguna vez ver el día en el que su aire dulce dará placer a sus ojos [...]; y el otro, en cambio, ordena a sus ojos que no vuelvan a verla (puntualización de la imagen).

\section{PETRARCA}

Così'l mio tempo infin qui trapassato

è in fiamma e'n pene; e quante utili oneste

vie sprezzai...

per servir questo lusinghier crudele!

... Che, s'i' non m'inganno, era

disposto a sollevarli alto da terra:

e' mi tolse di pace e pose in guerra.

[...] misero! A che quel caro ingegno altero

e l'alttre doti a me date dal cielo?

(Canzone CCCLX)

\section{BANCHS}

Me acordaba por quien tengo perdida la leve edad que al porvenir convida y el antiguo vigor que levantaba mi nombre entre los seres argentinos

(Soneto 17)

Lápida sin leyenda me anticipo, cual conviene a quien sigue una perdida labor, pues la mejor labor disipo llorando una pasión inextinguida. .

(Soneto 34)

Si yo naci para más alta empresa, que arrojar el honor de mis deseos a los ligeros pies de una belleza...

(Soneto 71) 
Elementos equivalentes: "quante utili oneste vie, sprezzai [ . . per servir questo lusinghier crudele!" y "por quien tengo perdida lí leve edad [...] / la mejor labor disipo/ llorando una pasión inextin guida"; "disposto a sollevarmi alto da terra" y "que levanta m nombre entre los seres argentinos"; "quel caro ingegno altero [al to] e l'altre doti a me date dal cielo?" y "si yo naci para más alti empresa'. Los dos se lamentan por haber sacrificado tiempo juventud yendo detrás de las cosas futiles perdiendo la ocasión d hacer cosas útiles y honestas. $\mathrm{P}$ aspira a alzarse de la tierra, se alguien, hacer grandes cosas; y $\mathrm{B}$ a alzar alto su nombre entr los seres argentinos. Ambos sienten que han nacido para empre sas más altas que la del simple amor por una mujer.

\author{
... alto pianeta \\ conven eh' i' segua a del mio campo mieta \\ luppole e stecchi... \\ (Soneto CLXV)
}

PETRARCA

\title{
BANCHS
}

Déjame con la frente pensativa contemplando en el prado de mi alma

(Soneto 71)

Elementos equivalentes: "l mio campo" y "el prado de $\mathrm{r}$ alma".

La imagen petrarquista del propio espacio interior, met forizado en un campo árido, se transforma, para B, en la un prado de su propia alma, un prado verde de pastoreo ( el cual parece representado el contexto argentino de la pam verde...)

PETRARCA

e'l vulgo, a me nemico et odioso...

(Soneto CCXXXIV)

Cercato ho sempre solitaria vita...

per fuggir questi ingegni sordi e loschi...

(Soneto CCLIX) 


\section{BANCHS}

Pero las multitudes, ¿qué me importan? ¿qué me importan las negras muchedumbres?

(Soneto 20)

Elementos equivalentes: "vulgo [...] nemico et odioso" y "negras muchedumbres"; "er fuggir" y "¿qué me importan?"

En $\mathrm{P}$ el vulgo, la plebe enemiga y odiosa, y en B "las multitudes", "las muchedumbres" que no le importan. Él también las desprecia como las desprecia P; pero en él se da la intensificación de la imagen respecto a la de $\mathrm{P}$ porque se repite, y al mismo tiempo, se dilata sonoramente ("las multitudes" $>$ "las muchedumbres").

\section{PETRARCA}

l'ho pien di sospir quest'aere tutto, d'aspri colli mirando il dolce piano ove nacque colei. .

(Soneto CCLXXXVIII)

\section{BANCHS}

Y veo el barrio donde está tu casa

(lo veo y la tristeza me traspasa)

(Soneto 25)

Elementos equivalentes: "sospir" y "tristeza"; "minado" y "veo"; "il dolce piano ove nacque colei" y "el barrio donde está tu casa".

La dulce llanura petrarquista (el contexto paisajista) donde ha nacido su amada, se convierte en $B$ en el barrio y la casa (el contexto urbano y doméstico) donde también su amada ha nacido; uno suspira de tristeza, el otro está traspasado por la tristeza (intensificación de la imagen).

\section{PETRARCA}

Celatamente Amor l'arco riprese, come uom ch'a nocer tempo e luogo aspetta...

Però, al mio parer, non gli fa onore ferir me de saetta in quello stato...

(Sonetos II y III)

\section{BANCHS}

Contempla, vida, el daño que me has hecho

... ¿Acaso piensas que es hazaña noble encorvar la altivez en carne humana?... 


\section{... puesto que clavas tanta saeta de oro en este flanco indigno}

(Soneto 84)

Elementos equivalentes: "nocer" y "daño"; "non gli fa onore' y "¿piensas que es hazaña noble?"; "ferir" y "clavas"; "saet ta" y "saeta".

Uno se dirige al Amor que lo ha traspasado, el otro a la vid. que lo ha maltratado. Uno dice: "no te da honor el haberme he rido con tu saeta"; el otro pregunta: "¿Crees que es algo nobl humillar a un hombre y traspasarlo con tal saeta?". El herir s convierte en traspasar ("clavar") (intensificación de la imagen).

\section{PETRARCA}

I' la riveggio starsi umilmente

$[\ldots]$

come chi teme...

Deposta avea l'usata leggiadria, le perle e le ghirlande e i panni allegri e'l riso e'lcanto...

(Soneto CCXLIX)

\section{BANCHS}

Dime por qué estás pálida, ¿has llorado?

Es como tenue cera y desaliento

de pétalos tu rostro sin contento...

(Soneto 40).

Elementos equivalentes: "umilmente" y "pálida"; "teme", "desaliento"; "ghirlande" y "pétalos"; "deposta avea l'usa leggiadria [...] e il riso e il canto" y "rostro sin contento".

En uno la mujer está allí, humilde, como temerosa; en el otr está pálida (como tenue cera o desaliento de pétalos). La actitı gestual de la humildad y del temor se vuelve cromatismo (pa dez), mientras la primera connotación comparativa ("como ten cera') lo intensifica (pálida > cérea) y la segunda lo vuelve más rico aún ("como desaliento de pétalos).

\section{PETRARCA}

Quel vago, dolce, caro, onesto sguardo dir parea: "To' di me quel che tu pòi; ché mai più qui non mi vedrai...

(Soneto CCCXXX) 


\section{BANCHS}

Dime por qué estás pálida, ¿has soñado esos sueños que son presentimiento de ausencia?...

(Soneto 40)

Elementos equivalentes: "Ché mai più! qui non mi vedrai" y "que son presentimientos de ausencia".

En uno 'ya no me verás', en el otro 'tengo el presentimiento de que nunca más me volverás a ver': de la certeza al presentimiento; del dramatismo al lirismo.

\section{PETRARCA}

Alma felice, che sovente torni a consolar le mie notti dolenti con gli occhi tuoi...

(Soneto GCLXXXII)

\section{BANCHS}

Pálida que en las largas noches solas lejos de todos imploré y bendije y que envuelta en un leve azul de aureolas viniendo adonde estoy tanto he previsto...

(Soneto 40)

Elementos equivalentes: "notti dolenti" y "largas noches solas" (insomnes); "alma felice" y "envuelta en un leve azul de aureolas"'; "torni a consolar"' y "viniendo adonde estoy".

Antes que nada la imagen sintética y puntual "Alma felice", de $\mathrm{P}$ se disuelve líricamente en la otra, analítica, de "envuelta en un leve azul de aureola" (de la síntesis al análisis). Inversamente la locución verbal frecuentativa "torni a consolar" se puntualiza en el rígido hic et nunc "viniendo adonde estoy". A su vez la imagen, aun sintética y dramática, de las "notti dolenti" se diluye y se vuelve lírica en "largas noches solas".

\section{PETRARCA}

$[\ldots]$

Donna, de' be' vostr'occhi il lume spento

e i cape' d'oro fin farsi d'argento... (Soneto XII) 


\section{BANCHS}

Y cuando la vejez tranquila y fría de color virginal te haga una aureola...

(Soneto 83)

Elementos equivalentes: "capei d'oro [...] farsi d'argento" , "de color virginal te haga una aureola"; "il lume spento" y "li vejez tranquila y fría".

En el cambio de "lume spento" (luz apagada de los ojos) : "vejez tranquila y fría" encontramos una desmetaforización de le imagen. Los "cabellos" que se vuelven "aureola" representar - en cambio - una metaforización de la imagen, y su color de piat: que pasa a "virginal" (cándido) representa una intensificación d. la metáfora.

\section{PETRARCA}

Dicemi spesso il mio fidato speglio l'animo stanco e la cangiata scorza, e la scemata mia destrezza e forza:

"Non ti nasconder più!; tu se' pur veglio

Obedir a natura in tutto è il meglio, eh' a contender con lei 'l tempo ne sforza»... (Soneto CCCLXI)

\section{BANCHS}

Carne mortal, sosiega.

Carne mortal, escucha la palabra

de la traición que aquí en ti misma labra

el término al que vas altiva y ciega.

Pues la traición es tu fugacidad y tu ilusión engaño de distancia.

Detente, ioh carne! y descoyunta el ansia de esa tu fuerte alada vanidad.

(Soneto 28)

Elementos equivalentes: "scorza" y "carne mortal"; "la ac mata mia destrezza e forza" y "sosiega [...]"; "tu se' pur v glio/obedir a natura in tutto è il meglio" y "detente $[. .$.$] y de$ coyunta el ansia".

La petrarquista "scorza", la corteza del alma (el cuerpo) vuelve en B "carne mortal"' (desmetaforización de la imagen 
y "obedir a natura in tutto è il meglio" trova su pendant en "sosiega" (cálmate, tranquilízate, serénate: estás ya cansada). En los dos poetas existe una afligida tristeza, ¡ay!, porque la llama de la juventud se apaga y, al mismo tiempo, existe una profunda filosofía de la resignación...

En B tenemos otra prueba, directa esta vez, de su conocimiento y de su amor por Petrarca en el soneto 36 que le ha dedicado enteramente:

Espíritu gentil que de Valclusa las selvas de laurel paseaste tanto, razonando de amores con la musa que alargaba el honor de su quebranto:

como a ti me ha dejado una confusa esperanza materia para el llanto, mas no me dio el ingenio asaz excusa para hacerla materia de mi canto.

Maestro soy en el amar doliente, aunque no en la elegancia del estilo ni en la ilustre nobleza del dictado;

pero viendo el laurel que honra tu frente, pienso, grave y tranquilo, que un sentimiento igual nos ha acercado.

En el argentino, la humildad ante el sumo poeta italiano está acompañada por la conciencia de la afinidad poética y existencial (el "sentimiento igual"). Es ese puente espiritual y estético que, a distancia de seis siglos, une y hermana milagrosamente a dos creaturas poéticas que vibran en la misma largueza de onda, en la misma sintonía.

\section{Conclusiones}

Hemos visto surgir de los textos analizados una serie de tendencias estilísticas y espirituales que pueden orientarnos hacia una posible clave de lectura. Aunque de orden diverso, ellas son: sustantivación del verbo, concreción y agudización de la imagen, especialización y concentración de la temporalidad y dilatación 
de la espacialidad, puntualización, intensificación, metaforización...

¿Cuál puede ser, entonces, esta clave de lectura?

Podemos decir que, en el conjunto, lo que lo caracteriza comparándolo con Petrarca es el hecho de que, dentro de la dialéctica poética lirismo/dramaticidad, tiende a prevalecer la segunda; mientras que en el italiano parece prevalecer la primera. El lirismc petrarquista, no exento del drama de la vida (y de la poesía que la interpreta transfigurándola), se dramatiza ulteriormente er Banchs; no tanto en el sentido de la teatralidad cuanto en el de pathos, de la angustia existencial; la que se coloca en la línea d ese "amar doliente" que, quizás bajo falsas apariencias, sea e carácter dominante del alma argentina. Pero esto es un tema que se tendrá que profundizar...

Giovanni Meo Zilic Università degli Studi di Venezii 